\title{
Understanding a prevention network in a local government area: Insights From a Social Network Analysis Among Western Australian Nutrition, Physical Activity, and Obesity Prevention Programs
}

Jonine Jancey, PhD (iD), Abbie-Clare Vidler, BSc Hons, Justine E. Leavy, PhD,

Dan Chamberlain, PhD, Therese Riley, PhD, Christina M. Pollard, PhD, Megan Milligan, MHP, Krysten Blackford, PhD

\begin{abstract}
This study aimed to use systems thinking tools to understand network relationships to inform strategies to improve nutrition, physical activity and obesity prevention services in a Western Australian local government area (LGA).: An audit of nutrition, physical activity and obesity prevention programs was conducted, and identified organisations were invited to participate in an organisational network survey. Social network analysis (SNA) determined the extent to which organisations shared information, knowledge, and resources; engaged in joint program planning; and applied for and shared funding, and operational barriers and contributors were identified. SNA data were mapped and analysed using UCINET 6 and Netdraw software. Five organisations within the network were identified as core, the remainder were periphery. Organisation one had the greatest influence in each of the networks measured. The strongest networks were for sharing information and the weakest was for funding. The connections were centralised to one organisation, enabling them to readily influence other organisations and impact network operations. Remaining organisations indicated limited partnership across the networks measured. Strengthened collaborations and partnerships are essential for health promotion, as they extend the reach and capabilities of organisations. This research indicated a need for stronger relationships between organisations and a reorientation of partnerships to facilitate resource sharing within local government areas, to improve nutrition, physical activity and obesity prevention efforts in practice.
\end{abstract}

Keywords: Obesity, social network analysis, partnerships, physical activity, nutrition

\section{Background}

Poor nutrition, physical inactivity and overweight/obesity are common risk factors for NonCommunicable Diseases (NCDs), with more than 1.9 billion people globally classified as overweight/obese in 2016 (Australian Institute of Health and Welfare, 2018; Di Angelantonio et al., 2016; 2013; World Health Organization, 2018). In Australia, two-thirds of adults (67\%) fall within the classifications of overweight/obesity, equating to 12.5 million people (Australian Bureau of Statistics, 2018). The indirect and direct costs amounted to $\$ 8.6$ billion in 2011-12, which is estimated to increase to $\$ 87.7$ billion by 2025 should no further preventative action be taken in Australia (PwC Australia, 2015). 
Obesity is a complex issue, resulting from an interplay between socioecological factors (Australian Institute of Health and Welfare, 2018). The built environment, occupation type, and available food and physical activity options are just some of the factors enmeshed with an individual's ability to meet dietary guidelines and engage in recommended levels of physical activity for health benefit (Committee on Evaluating Progress of Obesity Prevention, Food, Nutrition, \& Institute of, 2013; Dalle Grave, Centis, Marzocchi, El Ghoch, \& Marchesini, 2013). It is therefore vital to consider behavioural, social and environmental influences that impact obesity (Australian Institute of Health and Welfare, 2018)

Yet, many organisations implementing prevention activities tend to favour behaviour change programs focusing on risk factors such as poor nutrition and inadequate physical activity levels, to address overweight/obesity (Dalle Grave et al., 2013; Swinburn, Caterson, Seidell, $\&$ James, 2004). These types of programs can be difficult to sustain in the long-term, and have been found to have limited success (Committee on Evaluating Progress of Obesity Prevention et al., 2013; Gray et al., 2017; Khanal et al., 2016). In addition there is a tendency for organisations to work in a siloed manner, limiting their interaction with other groups or sectors to affect change, often competing for minimal and/or the same funding (Bevc, Retrum, \& Varda, 2015; Butcher et al., 2014; Nader et al., 2012; Reicks, Trofholz, Stang, \& Laska, 2014). Insufficient funding also supports competitive program design, with organisations at times seeking to implement prevention strategies in which they can justify their influence on health and maintain funding (Kania \& Kramer, 2011).These stand-alone programs can waste limited resources and saturate the prevention space with duplicative interventions (Kania \& Kramer, 2011; Whelan et al., 2015).

Systems thinking has emerged within public health as a method to explore the interconnected factors which contribute to prevention, thus improving understanding of an issue in a broader context (Bensberg, Allender, \& Sacks, 2020; Valente, 2010 ). Systems thinking can determine the relationships between actors (e.g. individuals or organisations), facilitating discussions which can lead to a better understanding of the shifting influences that exist and affect a network's operation (Bensberg, Joyce, \& Wilson, 2021; Carey et al., 2015). A network's structure can be explored using social network analysis (SNA), which can assist in developing an understanding of the opportunities and constraints placed on individuals and organisations and the roles they play in the outcomes of the network (Borgatti, Everett, \& Johnson, 2018; Valente, 2010).

Understanding prevention initiatives and collaborations between organisations is particularly important considering the need for partnership to address inherently complex issues, such as risk factors for NCDs (Riley, Hopkins, Gomez, Davidson, \& Chamberlain, 2018; Roussy, Riley, \& Livingstone, 2019). By understanding the ways in which these partnerships function, efforts to improve health can be better understood, discussed and potentially strengthened (Committee on Evaluating Progress of Obesity Prevention et al., 2013)

\section{Purpose}


This study aimed to use systems thinking tools to understand network relationships to inform discussions and policy and practice to improve nutrition, physical activity and overweight /obesity prevention activities in a Western Australian local government area (LGA).

\section{Methods}

The Systems Change Framework (Davidson \& Morgan, 2018), a cyclical, iterative process, guided the research methodology for the study. The Framework comprised four stages: a) defining the situation (establishing boundaries and context); b) gaining clarity (identifying actors and exploring relationships); c) finding leverage (identifying strengths and opportunities); and d) acting strategically (discussing actions to build strength in the network). Approval for the research was obtained from the Curtin University Human Research Ethics Committee (approval number HRE2017-0862).

\section{Defining the situation}

The boundary of the study was a LGA encompassing eight metropolitan suburbs in Perth, WA. The LGA had a population of 36,549 people, comprised largely of adults aged 20-40 years $(44 \%)$, with most classified as overweight or obese $(60.5 \%)$. Chronic disease among residents, included heart disease (4.6\%), diabetes (3.8\%) and cancer (3.5\%).(South Metropolitan Health Service, 2016) The majority of residents did not meet the recommended intake of vegetables (91\%) or fruit (51\%)(National Health and Medical Research Centre, 2013), and 32\% were insufficiently active(South Metropolitan Health Service, 2016).

\section{Gaining clarity}

Phase 1-Network Inventory: An advisory committee comprising the research team, obesity experts, community health promotion officers and those working in the local government area (health promotion practitioners and policy makers) used a nominal group technique(LeeHan H, Dwyer J, \& Johnson I, 1996) to identify organisations within the LGA based on the frequency they contributed to nutrition, physical activity and overweight/obesity prevention activities. Activities were included (policy regulation or program) if they were current, conducted in the LGA, comprised more than one session (indicating an ongoing nature) and were population based (not one-on-one). The appropriate person from the identified organisations was contacted and invited to participate in a face-to-face interview at their worksite. Participants were provided with an information sheet, and informed consent was obtained prior to the interview.

\section{Data collection}

The interviews took between 1 to 2 hours to complete and the data were entered into custombuilt software. The inventory (Riley et al., 2018)captured data on the profile of the contact person, type of activity, activity's objectives (e.g., awareness raising, influencing attitudes, increasing knowledge, behaviour change, partnership development), and strategies (e.g. unpaid, paid and social media, policy/legislation change, advocacy, online/printed resources, education session), and funding type (charity, local, state and federal, philanthropic). These data were used to inform the second phase of the project (Davidson \& Morgan, 2018). 
Phase 2 - Organisational Network Survey: The staff members within each identified organisation from the systems inventory were contacted via telephone to discuss the second phase of the study, and to provide informed consent. After being emailed the survey a week was provided for completion. To increase the likelihood that a response rate of at least $75 \%$ was achieved and the network data could be classified as reliable (Borgatti, Carley, \& Krackhardt, 2006), two to three reminder telephone calls were carried out.

\section{Data collection}

The online organisational network survey (ONS) was adapted from previous Australian community projects (Davidson \& Morgan, 2018; Milward \& Provan, 1998), and sought to obtain information on the organisations sharing of information, knowledge or resources; engagement in joint program planning and implementation; using an organisational network roster which ranked relationship strength as 'high', 'medium', 'low' or 'none'. Participants were also asked to nominate barriers and contributors to implementing physical activity, nutrition, and obesity prevention activities (Bess, 2015; Qualtrics, 2018). This instrument is available on request from the authors.

The ONS was reviewed by the expert advisory committee to establish face and content validity. The instrument was checked for comprehension by six representatives from a health promotion organisation whose staff were no involved in the research. Following consolidation of the feedback, the ONS was trialled with Health Promotion Officers $(n=10)$ working in the health service to test functionality

\section{Data Analysis}

Data collected from the inventory were entered into SPSS and frequencies and proportions were calculated. ONS data were mapped and analysed using UCINET 6 and Netdraw software (Borgatti, 2002; Borgatti, Everett, \& Freeman, 2002). Each of the network relationships (Borgatti et al., 2018) (share information or knowledge; share resources; joint planning or running joint programs; receiving funding; providing funding; sharing funding or applying for shared funding) were combined (Dickison, Magnani, \& Rossi, 2016) to create a composite network. Organisation responses to barriers and contributors were analysed using descriptive statistics in SPSS.

The relationships between organisations (nodes) were measured using the composite network. This analysis allowed the position of organisations relative to others to be determined, as well as identifying the general structure of the network. We identified the average degree - the average number of ties for each organisation; Density - proportion of ties between organisations; Diameter - Shortest pathway between two organisations furthest from each other in the network; and Reciprocity - extent to which a relationship between two organisations is nominated as present by both (Borgatti et al., 2018; Hanneman \& Riddle, 2005; Hawe, Webster, \& Shiell, 2004). These measures detail the frequency organisations were nominated by respondents and assists in determining an organisations influence in a network and overall system cohesion (Borgatti et al., 2018; Valente, 2010). Core-periphery analysis was conducted to segment core organisations with the strongest connections to one another within the network (core nodes), from those that are the least connected (periphery nodes) (Borgatti et al., 2018). 


\section{Results}

Phase 1: Prevention Activities in the LGA

A total of 35 prevention activities were identified in the LGA, 13 nutrition, 14 physical activity and eight obesity. Table 1 provides a summary of the objectives and strategies used by each program.

Table 1: Prevention Program Objectives and Strategies within a Local Government Area $(\mathbf{n}=15)$

\begin{tabular}{|c|c|c|c|c|c|c|c|c|}
\hline & \multicolumn{2}{|c|}{$\begin{array}{l}\text { Total } \\
n=35\end{array}$} & \multicolumn{2}{|c|}{$\begin{array}{c}\text { Nutrition } \\
n=13\end{array}$} & \multicolumn{2}{|c|}{$\begin{array}{c}\text { Physical } \\
\text { activity } \\
n=14\end{array}$} & \multicolumn{2}{|c|}{$\begin{array}{c}\text { Obesity } \\
n=8\end{array}$} \\
\hline & $\mathbf{n}$ & $\%$ & $\mathbf{n}$ & $\%$ & $\mathbf{n}$ & $\%$ & $\mathbf{n}$ & $\%$ \\
\hline \multicolumn{9}{|l|}{ Program Objectives } \\
\hline Influence attitudes & 35 & 100 & 13 & 100 & 14 & 100 & 8 & 100 \\
\hline Change behaviour & 35 & 100 & 13 & 100 & 14 & 100 & 8 & 100 \\
\hline Increase knowledge & 33 & 94.3 & 13 & 100 & 12 & 85.7 & 8 & 100 \\
\hline Build skills & 33 & 94.3 & 12 & 92.3 & 13 & 92.9 & 8 & 100 \\
\hline Raise awareness & 31 & 88.6 & 11 & 84.6 & 12 & 85.7 & 8 & 100 \\
\hline Partnership development & 31 & 88.6 & 11 & 84.6 & 13 & 92.9 & 7 & 87.5 \\
\hline Encourage enrolment & 20 & 57.1 & 5 & 38.5 & 7 & 50 & 8 & 100 \\
\hline Influence changes to built environment & 20 & 57.1 & 6 & 46.2 & 9 & 64.3 & 5 & 62.5 \\
\hline Advocate change & 12 & 34.3 & 5 & 38.5 & 5 & 35.7 & 2 & 25 \\
\hline Develop regulation & 5 & 14.3 & 2 & 15.4 & 1 & 7.1 & 2 & 25 \\
\hline \multicolumn{9}{|l|}{ Program Strategies } \\
\hline Online communications & 33 & 94.3 & 12 & 92.3 & 13 & 92.9 & 8 & 100 \\
\hline Establish partnerships & 32 & 91.4 & 12 & 92.3 & 13 & 92.9 & 7 & 87.5 \\
\hline Social media & 31 & 88.6 & 12 & 92.3 & 12 & 85.7 & 14 & 100 \\
\hline Unpaid media & 30 & 85.7 & 11 & 84.6 & 12 & 85.7 & 7 & 87.5 \\
\hline Printed resources & 30 & 85.7 & 11 & 84.6 & 12 & 85.7 & 7 & 87.5 \\
\hline Group education sessions & 29 & 82.9 & 11 & 84.6 & 11 & 78.6 & 7 & 87.5 \\
\hline Telephone support & 26 & 74.3 & 8 & 61.5 & 12 & 85.7 & 6 & 75 \\
\hline
\end{tabular}




\begin{tabular}{|c|c|c|c|c|c|c|c|c|}
\hline Online resources & 25 & 71.4 & 10 & 76.9 & 10 & 71.4 & 5 & 62.5 \\
\hline Referral services & 16 & 45.7 & 5 & 38.5 & 7 & 50 & 4 & 50 \\
\hline Incentives & 15 & 42.9 & 5 & 38.5 & 6 & 42.9 & 4 & 50 \\
\hline Policy or guidelines & 14 & 40 & 4 & 30.8 & 8 & 57.1 & 2 & 25 \\
\hline Signage & 13 & 37.1 & 4 & 30.8 & 6 & 42.9 & 3 & 37.5 \\
\hline Paid media & 8 & 22.9 & 1 & 7.7 & 4 & 28.6 & 3 & 37.5 \\
\hline School curriculum & 7 & 20 & 3 & 23.1 & 2 & 14.3 & 2 & 25 \\
\hline \multicolumn{9}{|l|}{ Funding sources } \\
\hline Charity & 1 & 2.9 & 1 & 7.7 & 0 & 0 & 0 & 0 \\
\hline Federal government & 3 & 8.6 & 1 & 7.7 & 1 & 7.1 & 1 & 12.5 \\
\hline State government & 5 & 14.3 & 4 & 30.8 & 0 & 0 & 1 & 12.5 \\
\hline Local government & 3 & 8.6 & 2 & 15.4 & 1 & 7.1 & 0 & 0 \\
\hline Philanthropic & 5 & 14.3 & 3 & 23.1 & 1 & 7.1 & 1 & 12.5 \\
\hline
\end{tabular}

Social Network Analysis

\section{Characteristics}

Fourteen (93\%) of the 15 organisations completed the ONS. The majority were nongovernment organisations (NGOs) $(n=11,73 \%)$ and the remainder were government organisations $(n=3,20 \%)$. The respondents identified as Coordinators (community, health promotion, program) $(n=5,36 \%)$, Managers (state, centre, program, prevention) $(n=4,29 \%)$, and Officers (executive or program) $(n=3,21 \%)$.

\section{Cohesion}

On average each organisation was aware of six of the 15 organisations identified in the ONS. Table 2 shows the cohesion measures for the composite network and within networks (share information or knowledge; share resources; joint planning or running joint programs; receiving funding; providing funding; sharing funding or applying for shared funding). Density for this network was 0.371 , reciprocity for the network as a whole $74.4 \%$. The 'sharing information or knowledge network' produced the same results as the 'composite network'. Each subsequent network was reduced in its degree, density and centralisation, though the 'joint planning network' had the highest value for degree centralization. The three funding networks (providing funding, receiving funding and sharing funding or applying for funding) scores were the lowest with density values ranging between 3.3-5.7\% and average degree values of 0.5-0.8. Centralisation for these networks was highest for the 'providing funding network' (0.291), followed by 'receiving funding network' $(0.286)$ and 'sharing funding network' (0.264). Figure 1 depicts the three non-government and two government 
organisations identified as core $(n=5)$ (most connected within network) and periphery $(n=9)$ (least connected within network) organisations.

Table 2. Cohesion across networks

\begin{tabular}{lccccccc}
\hline & $\begin{array}{c}\text { Compos } \\
\text { ite } \\
\text { Network }\end{array}$ & $\begin{array}{c}\text { Share } \\
\text { information } \\
\text { or knowledge } \\
\text { network }\end{array}$ & $\begin{array}{c}\text { Share } \\
\text { resources } \\
\text { network }\end{array}$ & $\begin{array}{c}\text { Joint } \\
\text { planning, } \\
\text { or running } \\
\text { joint } \\
\text { programs } \\
\text { network }\end{array}$ & $\begin{array}{c}\text { Providing } \\
\text { funding } \\
\text { network }\end{array}$ & $\begin{array}{c}\text { Receiving } \\
\text { funding } \\
\text { network }\end{array}$ & $\begin{array}{c}\text { Sharing } \\
\text { funding or } \\
\text { applying } \\
\text { for shared } \\
\text { funding } \\
\text { network }\end{array}$ \\
\hline Average Degree & 5.2 & 5.2 & 4.3 & 3.8 & 0.5 & 0.5 & 0.8 \\
\hline Density & $37 \%$ & $37 \%$ & $31 \%$ & $27 \%$ & $3.3 \%$ & $3.8 \%$ & $5.7 \%$ \\
\hline Diameter & 3 & 3 & 4 & 3 & 3 & 2 & 4 \\
\hline $\begin{array}{l}\text { Degree } \\
\text { Centralisation }\end{array}$ & 0.643 & 0.643 & 0.632 & 0.676 & 0.291 & 0.286 & 0.264 \\
\hline Reciprocity (\%) & 74.4 & 74.4 & 73.8 & 70.2 & 28.6 & 0 & 16.7 \\
\hline
\end{tabular}




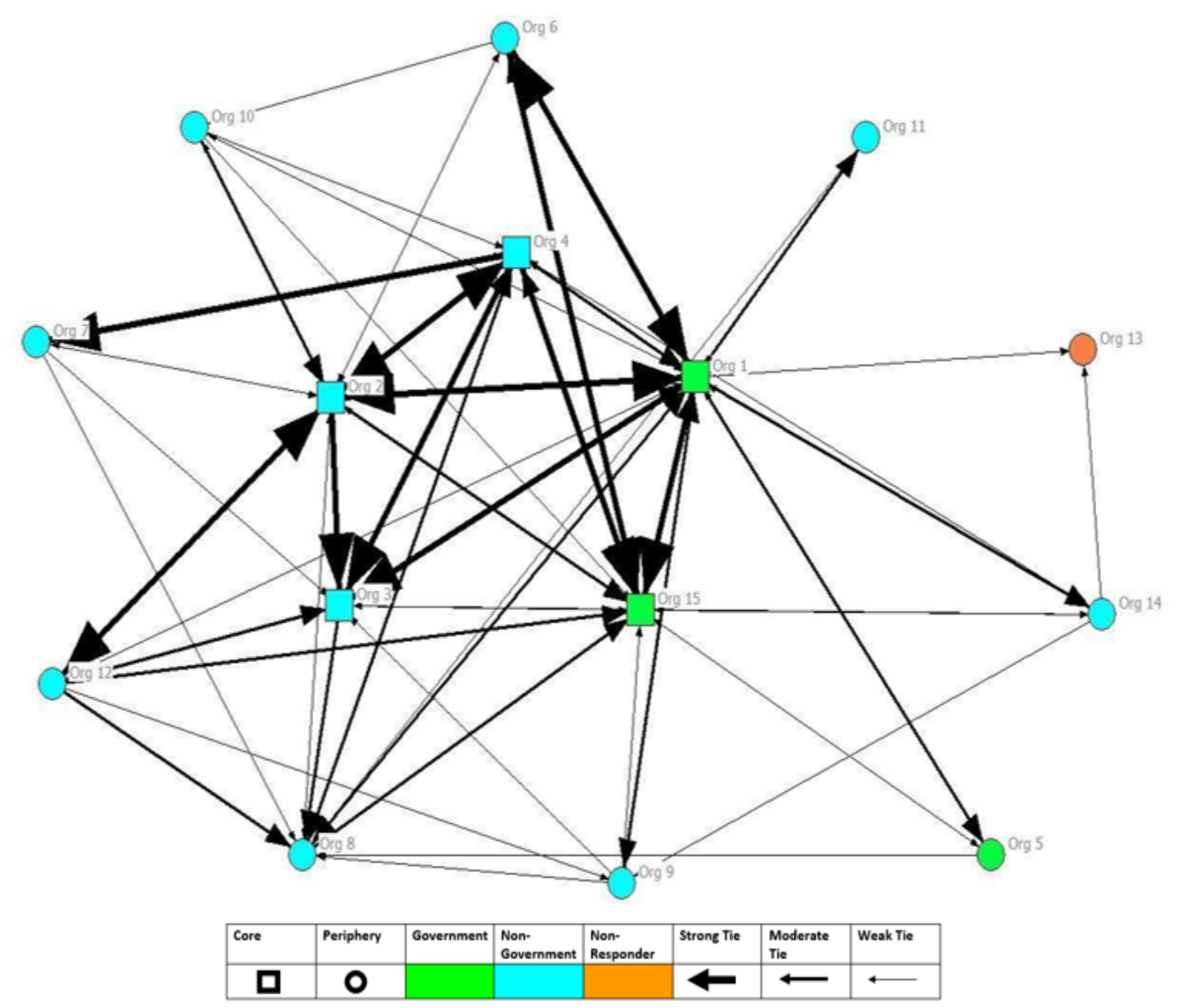

Figure 1. The whole network and strength of relationship between organisations.

\section{Barriers and Contributions}

The most frequently nominated barriers to implementing nutrition, physical activity and obesity prevention were: 'insufficient funding' $(n=11)$; 'limited staffing' $(n=11)$; 'limited capacity of partner organisations' $(n=5)$; 'insufficient collaborations and partnerships' $(n=4)$; 'political feasibility' $(n=4)$; 'not enough volunteers/volunteer staff' $(n=3)$; 'insufficient community connections' ( $n=3)$; and 'lack of IT/web resources' $(n=3)$.

The nominated highest-ranking contributions by organisations to implementing nutrition, physical activity and obesity prevention programs were 'developing health policy', 'health prevention data', 'funding', 'advocacy', 'expertise other than health', 'facilitation/leadership', 'nutrition expertise', 'program support and coordination', 'paid staff' and 'in-kind resources'.

\section{Discussion}

This study assessed the nutrition, physical activity and obesity prevention network within a metropolitan LGA in Perth, WA. Guided by the System Change Framework (Davidson \& Morgan, 2018), the bounded system was defined and relationships between organisations 
within the network were explored with the objective of using this data to identify opportunities that could stimulate discussions to facilitate strategic actions to increase collaborative work.

Both government $(n=4)$ and non-government organisations $(n=11)$ were identified as being active in conducting nutrition, physical activity, and obesity prevention programs in this network. The intervention activities aimed to incorporate a range of behavioural and environmental initiatives to support healthier lifestyles. Of the 35 prevention activities identified in the LGA, the nominated objectives were predominantly aimed at changing behaviours $(n=35)$, influencing attitudes $(n=35)$ and increasing skills and knowledge $(n=33)$. Conversely, few organisations identified advocacy $(n=12)$ and policy reform $(n=5)$ as objectives. The activities were predominantly implemented through an assortment of media strategies and resource development. Although these strategies are not recognised as being inherently ineffective, a more comprehensive approach to prevention encompassing a broader range of objectives and strategies could strengthen their impact (Whelan et al., 2015). The synthesis of current prevention approaches also presents an opportunity for extending the capabilities of organisations by allowing skills and resources to be better harnessed to meet the diverse needs of a population, creating an environment that supports positive health outcomes (Anaf et al., 2014; Corbin, Jones, \& Barry, 2018). A whole of system approach using a multi-faceted interconnected response would certainly provide the greatest opportunity to address risk factors and improve health of the community (Bensberg et al., 2020)

The researched network consisted of 15 identified organisations all working in physical activity, nutrition and obesity. Based on Borgatti's Theory, collaboration between organisations in this network's was lower than expected (Borgatti et al., 2018). Furthermore, on average each of the organisations in the network identified that they were aware of only six of the other organisations listed. This is surprising considering all of the organisations in the network identified nutrition, physical activity and obesity prevention as a priority and indicates an opportunity for more collaborative approaches to prevention. A potential leverage opportunity would be to raise organisations' awareness of others prevention activities, to foster increased collaboration.

There were five core organisations within the network (greatest connections), made up of three non-government and two government organisations. The remaining organisations $(n=9)$ were far less connected. Interestingly, while both core and periphery groups frequently selected limited funding and staffing as a barrier to implementing prevention activities, only periphery organisations indicated insufficient collaborations and partnerships and insufficient community connections as barriers. Core organisations were also more likely to select 'limited capacity of partner organisations' as a barrier to implementing programs. This also highlights opportunities for core Organisation 1 and other core organisations to facilitate partnerships and collaborations, perhaps reorientating the way partnerships are currently conducted.

The weakest whole networks identified were 'providing funding network', 'receiving funding network' and 'sharing funding network'. Parameters identified by Gessell and colleagues 
(Gesell, Barkin, \& Valente, 2013) suggest, the average degree value for a network should be greater than one, however, each of the funding networks in our study did not achieve this, ranging from 0.5 to 0.8 . Similarly, for a network to indicate a greater probability of mutual relationships between organisations, density values should be greater than $50 \%$ but no lower than 15\% (Gesell et al., 2013). The 'providing', 'receiving' and 'sharing funding' networks in the system also fell outside this range. This is not surprising, given the increasing disinvestment in NCD prevention and the strong competition to access the mere $6 \%$ available within the $\$ 181$ billion Australian healthcare budget (Bagnall et al., 2019; Di Angelantonio et al., 2016). Consideration of opportunities to apply for joint funding and collaborate on such projects warrant exploration and discussion.

\section{Study limitations}

We may have failed to capture all organisations and the prevention programs operating within the LGA, however, we attempted to address this by seeking advice on who to include in the study from the Advisory Committee members, local HPOs and the organisations operating in the LGA. The cross-sectional data is a snapshot in time of the nutrition, physical activity and obesity prevention network of a metropolitan LGA, but it does provide insights into the network, which will inform future discussions and planning.

\section{Implications for practice and policy}

Collaboration and partnerships are an essential component of health promotion, as improved health outcomes and prevention of NCDs cannot be attained by any one organisation, given their inherent complexity. Therefore, collecting data on what is happening within a network, such as an LGA, is invaluable as it can inform open discussions across the networks organisations, which can facilitate collaborative planning of policy and practices to improve system operations.

In this research, the potential role of core organisations needs to be recognised. These organisations have the capacity to play a facilitation role in strengthening the system through supporting increased communication fostering collaborations and partnerships. Increased communication will raise awareness of other organisations in the network, their activities and provide opportunities for discourse around collaborative activities and potentially joint funding applications. Reorienting partnerships to facilitate resource and expertise sharing will also improve the ability of organisations to consolidate scarce resources and act strategically in addressing obesity and its associated risk factors in the network. The findings from this study will be provided to the participating organisations by the Health Promotion Officers working in the local government area.

Social network analysis can assist in understanding the complex area of NCD prevention but has had limited application. This social network study provides data that can discussed and actioned, thereby acting as a catalyst for change.

\section{References}


Anaf, J., Baum, F., Freeman, T., Labonte, R., Javanparast, S., Jolly, G., . . Bentley, M. (2014). Factors shaping intersectoral action in primary health care services. Aust N Z J Public Health, 38(6), 553-559. doi:10.1111/1753-6405.12284

Australian Bureau of Statistics. (2018). National Health Survey: First Results, 2017-18 Canberra Retrieved from http://www.abs.gov.au/ausstats/abs@.nsf/mf/4364.0.55.001

Australian Institute of Health and Welfare. (2018). Australia's Health 2018. Retrieved from https://www.aihw.gov.au/getmedia/7c42913d-295f-4bc9-9c24-4e44eff4a04a/aihw-aus221.pdf.aspx?inline=true

Bagnall, A. M., Radley, D., Jones, R., Gately, P., Nobles, J., Van Dijk, M., . . Sahota, P. (2019). Whole systems approaches to obesity and other complex public health challenges: a systematic review. BMC Public Health, 19(1), 8. doi:10.1186/s12889-018-6274-z

Bensberg, M., Allender, S., \& Sacks, G. (2020). Building a systems thinking prevention workforce. HPJA, 31, 436-446. doi:10.1002/hpja.325

Bensberg, M., Joyce, A., \& Wilson, E. (2021). Building a Prevention System: Infrastructure to Strengthen Health Promotion Outcomes. International journal of environmental research and public health, 18(4). doi:https://doi.org/10.3390/ijerph18041618

Bess, K. D. (2015). Reframing coalitions as systems interventions: A network study exploring the contribution of a youth violence prevention coalition to broader system capacity. American Journal of Community Psychology, 55(3-4), 381-395. doi:doi:10.1007/s10464-015-9715-1

Bevc, C. A., Retrum, J. H., \& Varda, D. M. (2015). New perspectives on the "Silo Effect": Initial comparisons of network structures across public health collaboratives. American Journal of Public Health, 105(S2), S230-S235. doi:10.2105/ajph.2014.302256

Borgatti, S. (2002). NetDraw Software for Network Visualization. Lexington, KY: Analytic Technologies. Retrieved from https://sites.google.com/site/netdrawsoftware/home

Borgatti, S., Carley, K. M., \& Krackhardt, D. (2006). On the robustness of centrality measures under conditions of imperfect data. Social Networks, 28(2), 124-136. doi:https://doi.org/10.1016/j.socnet.2005.05.001

Borgatti, S., Everett, M., \& Freeman, L. (2002). Ucinet for Windows: Software for Social Network Analysis (Version 6). Harvard; MA: Analytic Technologies. Retrieved from https://sites.google.com/site/ucinetsoftware/home

Borgatti, S., Everett, M., \& Johnson, J. (2018). Analyzing Social Networks (J. Seaman Ed. 2 ed.). London, UK: Sage Publications.

Butcher, L. M., Rose Chester, M., Michelle Aberle, L., Jo-Ann Bobongie, V., Davies, C., Louise Godrich, S., ... Begley, A. (2014). Foodbank of Western Australia's healthy food for all. British Food Journal, 116(9), 1490-1505. doi:doi:10.1108/BFJ-01-2014-0041

Carey, G., Malbon, E., Carey, N., Joyce, A., Crammond, B., \& Carey, A. (2015). Systems science and systems thinking for public health: A systematic review of the field. BMJ open, 5(12), e009002-e009002. doi:10.1136/bmjopen-2015-009002

Committee on Evaluating Progress of Obesity Prevention, E., Food, Nutrition, B., \& Institute of, M. (2013). Evaluating Obesity Prevention Efforts: A Plan for Measuring Progress. In L. W. Green, L. Sim, \& H. Breiner (Eds.), Evaluating Obesity Prevention Efforts: A Plan for Measuring Progress (pp. 255-271). Washington (DC): National Academies Press (US)

Copyright 2013 by the National Academy of Sciences. All rights reserved. 
Corbin, J., Jones, J., \& Barry, M. (2018). What makes intersectoral partnerships for health promotion work? A review of the international literature. Health Promotion International, 33(1), 4-26. doi:https://doi.org/10.1093/heapro/daw061

Dalle Grave, R., Centis, E., Marzocchi, R., El Ghoch, M., \& Marchesini, G. (2013). Major factors for facilitating change in behavioral strategies to reduce obesity. Psychology research and behavior management, 6, 101-110. doi:10.2147/PRBM.S40460

Davidson, S., \& Morgan, M. (2018). Systems Change Framework. Retrieved from Ultimo, NSW: https://preventioncentre.org.au/wp-content/uploads/2015/01/Systems-Change-Overvieww-Practices.pdf

Di Angelantonio, E., Bhupathiraju, S. N., Wormser, D., Gao, P., Kaptoge, S., de Gonzalez, A. B., ... Hu, F. B. (2016). Body-mass index and all-cause mortality: individual-participant-data metaanalysis of 239 prospective studies in four continents. The Lancet, 388(10046), 776-786. doi:https://doi.org/10.1016/S0140-6736(16)30175-1

Dickison, M. E., Magnani, M., \& Rossi, L. (2016). Multilayer Social Networks. New York: NY: Cambridge University Press.

Gesell, S. B., Barkin, S. L., \& Valente, T. W. (2013). Social network diagnostics: a tool for monitoring group interventions. Implement Sci, 8, 116. doi:10.1186/1748-5908-8-116

Gray, J., Hoon, E. A., Hossein Haji Ali, A., Spooner, C., Harris, M. F., \& Karnon, J. (2017). Is the Counterweight Program a feasible and acceptable option for structured weight management delivered by practice nurses in Australia? A mixed-methods study. Australian Journal of Primary Health, 23(4), 348-363. doi:http://dx.doi.org/10.1071/PY16105

Green, L., Sim, L., \& Breiner, H. (2013). Evaluating Obesity Prevention Efforts: A Plan For Measuring Progress. In. Washington: National Academies Press (US).

Hanneman, R., \& Riddle, M. (2005). Introduction to social network methods. In. Retrieved from https://faculty.ucr.edu/ hanneman/

Hawe, P., Webster, C., \& Shiell, A. (2004). A glossary of terms for navigating the field of social network analysis. Journal of Epidemiology and Community Health, 58(12), 971. doi:10.1136/jech.2003.014530

Kania, J., \& Kramer, M. (2011). Collective Impact. Stanford Social Innovation Review Retrieved from https://ssir.org/articles/entry/collective_impact

Khanal, S., Lloyd, B., Rissel, C., Portors, C., Grunseit, A., Indig, D., . . McElduff, S. (2016). Evaluation of the implementation of Get Healthy at Work, a workplace health promotion program in New South Wales, Australia. Health Promotion Journal of Australia, 27(3), 243-250. doi:10.1071/he16039

Lee-Han H, Dwyer J, \& Johnson I. (1996). Application of Nominal Group Technique to evaluate a community health status report. . The Canadian Journal of Progam Evaluation., 11(1), 139144.

Milward, H. B., \& Provan, K. G. (1998). Measuring Network Structure. Public Administration, 76(2), 387-407. doi:10.1111/1467-9299.00106

Nader, P. R., Huang, T. T.-K., Gahagan, S., Kumanyika, S., Hammond, R. A., \& Christoffel, K. K. (2012). Next Steps in Obesity Prevention: Altering Early Life Systems To Support Healthy Parents, Infants, and Toddlers. Childhood Obesity, 8(3), 195-204. doi:10.1089/chi.2012.0004

National Health and Medical Research Centre. (2013). Australian Dietary Guidelines. Retrieved from https://www.nhmrc.gov.au/about-us/publications/australian-dietary-guidelines 
PwC Australia. (2015). Weighing the cost of obesity: A case for action. Retrieved from https://www.pwc.com.au/publications/healthcare-obesity.html

Qualtrics. (2018). Qualtrics (Version March 2019). Provo, Utah, USA: Qualtrics. Retrieved from https://www.qualtrics.com

Reicks, M., Trofholz, A. C., Stang, J. S., \& Laska, M. N. (2014). Impact of cooking and home food preparation interventions among adults: outcomes and implications for future programs. J Nutr Educ Behav, 46(4), 259-276. doi:10.1016/j.jneb.2014.02.001

Riley, T., Hopkins, L., Gomez, M., Davidson, S., \& Chamberlain, D. (2018). Prevention Tracker: Final report to participants. Retrieved from https://preventioncentre.org.au/wpcontent/uploads/2016/05/PT-Participant-report-December-2018-FINAL.pdf

Roussy, V., Riley, T., \& Livingstone, C. (2019). Together stronger: boundary work within an Australian systems-based prevention initiative. Health Promotion International. doi:10.1093/heapro/daz065

South Metropolitan Health Service. (2016). Town of Victoria Park Health and Wellbeing Profile. Retrieved from https://yourthoughts.victoriapark.wa.gov.au/23350/documents/46761

Swinburn, B., Caterson, I., Seidell, J. C., \& James, W. P. (2004). Diet, nutrition and the prevention of excess weight gain and obesity. Public Health Nutr, 7(1a), 123-146.

Valente, T. W. (2010). Social networks and health: Models, methods, and applications. In. Retrieved from http://www.oxfordscholarship.com/view/10.1093/acprof:0so/9780195301014.001.0001/ac prof-9780195301014 doi:10.1093/acprof:oso/9780195301014.001.0001

Whelan, J., Love, P., Romanus, A., Pettman, T., Bolton, K., Smith, E., . . Allender, S. (2015). A map of community-based obesity prevention initiatives in Australia following obesity funding 20092013. Aust N Z J Public Health, 39(2), 168-171. doi:10.1111/1753-6405.12296

World Health Organization. (2018). Obesity and overweight. Retrieved from https://www.who.int/en/news-room/fact-sheets/detail/obesity-and-overweight 